\title{
Diameter of lodgepole pine and mortality caused by the mountain pine beetle: factors that influence their relationship and applicability for susceptibility rating
}

\author{
Niklas Björklund and B. Staffan Lindgren
}

\begin{abstract}
During outbreaks the mountain pine beetle (Dendroctonus ponderosae Hopkins) kills large lodgepole pine trees (Pinus contorta Dougl. ex Loud.) more frequently than smaller ones. There is, however, considerable variation in the relation of diameter to incidence of attack. In a meta-analysis of published data we found that the relationship was primarily determined by geographic location (elevation, latitude, and longitude). We propose a new tree mortality measure, the probability of death index, defined as the average percentage of mortality for trees $>23 \mathrm{~cm}$. The index may improve the precision in predictive modeling of tree mortality, as it provides a biologically relevant measure of mortality, since it only includes trees that contribute to the growth of an epidemic and is not influenced by the number of trees within a diameter class. To be useful to forest managers, it must be possible to predict the index from stand parameters that are easily measured. The usefulness of the index was supported by a meta-analysis, which showed that $53 \%$ of the variation in the mortality index was explained by geographic location. Tree density did not explain any additional variation. Future research is needed to evaluate the performance of the probability of death index compared with that of other mortality measures.
\end{abstract}

\begin{abstract}
Résumé : Durant les épidémies, le dendroctone du pin ponderosa (Dendroctonus ponderosae Hopkins) tue plus souvent les grosses tiges de pin tordu (Pinus contorta Dougl. ex Loud.) que les plus petites. Cependant, la relation entre le diamètre et l'incidence des attaques varie énormément. Dans une méta-analyse des données publiées, nous avons découvert que la relation est principalement déterminée par la position géographique (altitude, latitude et longitude). Nous proposons une nouvelle mesure de mortalité des arbres : l'indice de probabilité de mortalité, définie comme étant le pourcentage moyen de mortalité des tiges de plus de $23 \mathrm{~cm}$. L'indice peut améliorer la précision des modèles de prédiction de la mortalité des arbres parce qu'il fournit une mesure de la mortalité pertinente du point de vue biologique étant donné qu'il inclut uniquement les arbres qui contribuent à la croissance d'une épidémie et qu'il n'est pas influencé par le nombre d'arbres dans une classe de diamètre. Pour être utile aux aménagistes forestiers, l'indice doit pouvoir être prédit à partir de paramètres du peuplement qui sont facilement mesurables. L'utilité de l'indice est supportée par une méta-analyse qui montre que $53 \%$ de la variation de l'indice de mortalité est expliquée par la position géographique. La densité des arbres n'explique aucune variation additionnelle. D'autres travaux seront nécessaires pour évaluer la performance de l'indice de probabilité de mortalité comparativement à d'autres mesures de la mortalité.
\end{abstract}

[Traduit par la Rédaction]

\section{Introduction}

Most bark beetles that attack living trees seem to prefer certain tree sizes (Rudinsky 1962; van Hees and Holsten 1994). During epidemics of the mountain pine beetle (Dendroctonus ponderosae Hopkins), large lodgepole pine trees (Pinus contorta Dougl. ex Loud.) are killed more frequently than smaller ones (Hopping and Beall 1948). Potential rea-

Received 8 October 2008. Accepted 10 February 2009.

Published on the NRC Research Press Web site at cjfr.nrc.ca on 2 May 2009.

N. Björklund ${ }^{1,2}$ and B.S. Lindgren. Natural Resources and Environmental Studies Institute, University of Northern British Columbia, 3333 University Way, Prince George, BC V2N 4Z9, Canada.

${ }^{1}$ Corresponding author (e-mail: Niklas.Bjorklund@ekol.slu.se).

${ }^{2}$ Present address: Department of Ecology, Swedish University of Agricultural Sciences, P.O. Box 7044, S-750 07 Uppsala,

Sweden. sons for this pattern are that large trees may be preferentially attacked (Shepherd 1966; Geiszler et al. 1980; Mitchell and Preisler 1991; Preisler 1993), provide a larger landing surface (Hynum and Berryman 1980), or have a larger basal area (Safranyik et al. 1975; Burnell 1977; Coulson 1979). Large diameter trees usually have thick phloem providing high beetle reproduction potential (Amman 1969, 1972; Katovich and Lavigne 1986; and Shrimpton and Thomson (1985) for specific situations when this is not the case). In addition, beetle survival is greater in large than small trees, even when the former have thin phloem (Reid 1963). Lower larval mortality rates in larger trees are likely attributable to the protection against cold temperatures and dessication provided by the thicker bark (Cole 1975, 1981). Thick bark also protects beetle larvae from the parasitoid Coeloides dendroctoni Cushman (Hymenoptera: Braconidae), which has a relatively short ovipositor (Reid 1963; Cole 1981).

Since tree diameter is related both to beetle reproduction and to larval survival, there should be a relationship between 


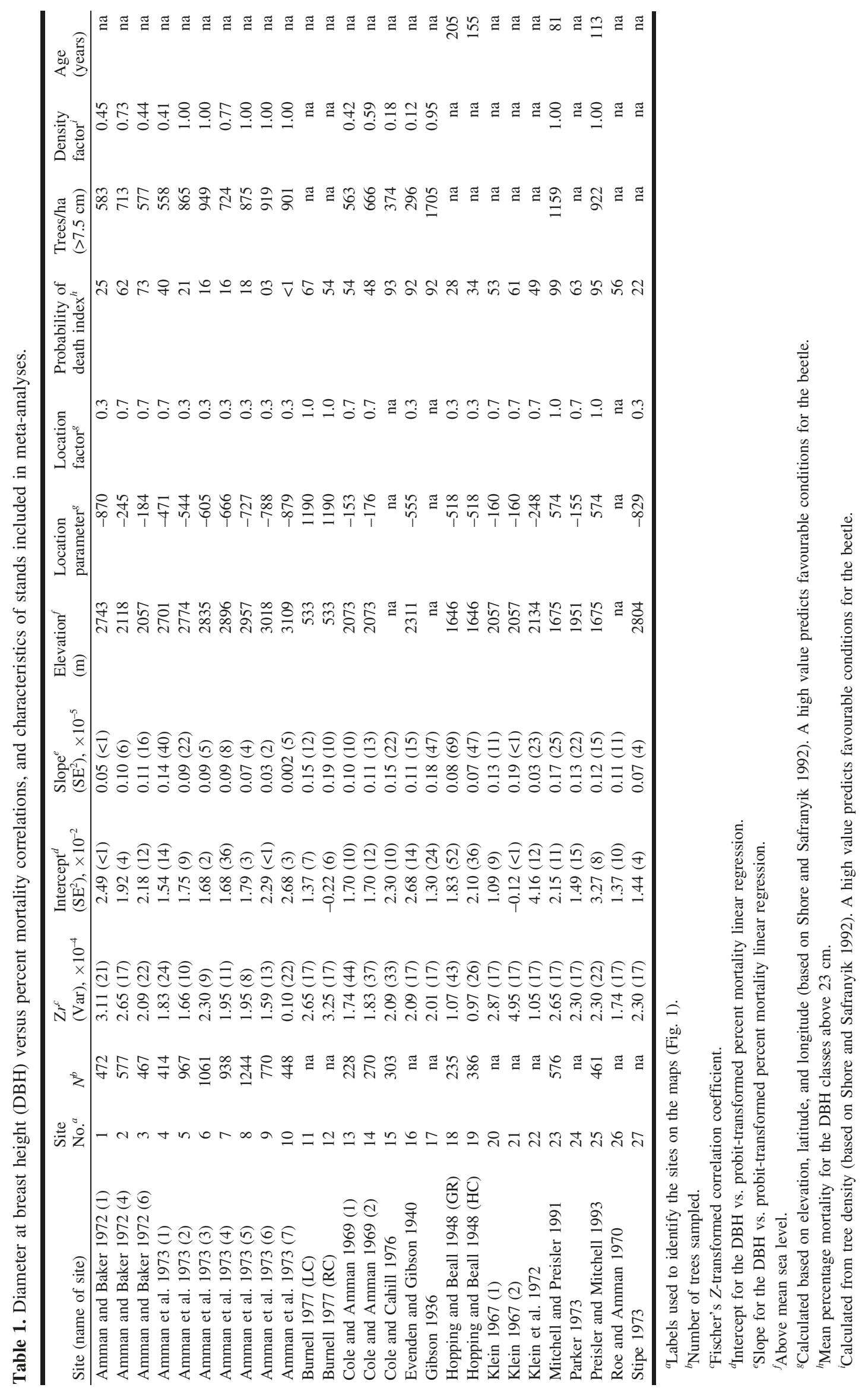


Fig. 1. Map of western United States and Canada showing the location of the sites used in the meta-analyses evaluating the influence of the location factor (based on Shore and Safranyik 1992) on tree mortality patterns. The sites are numbered according to Table 1.

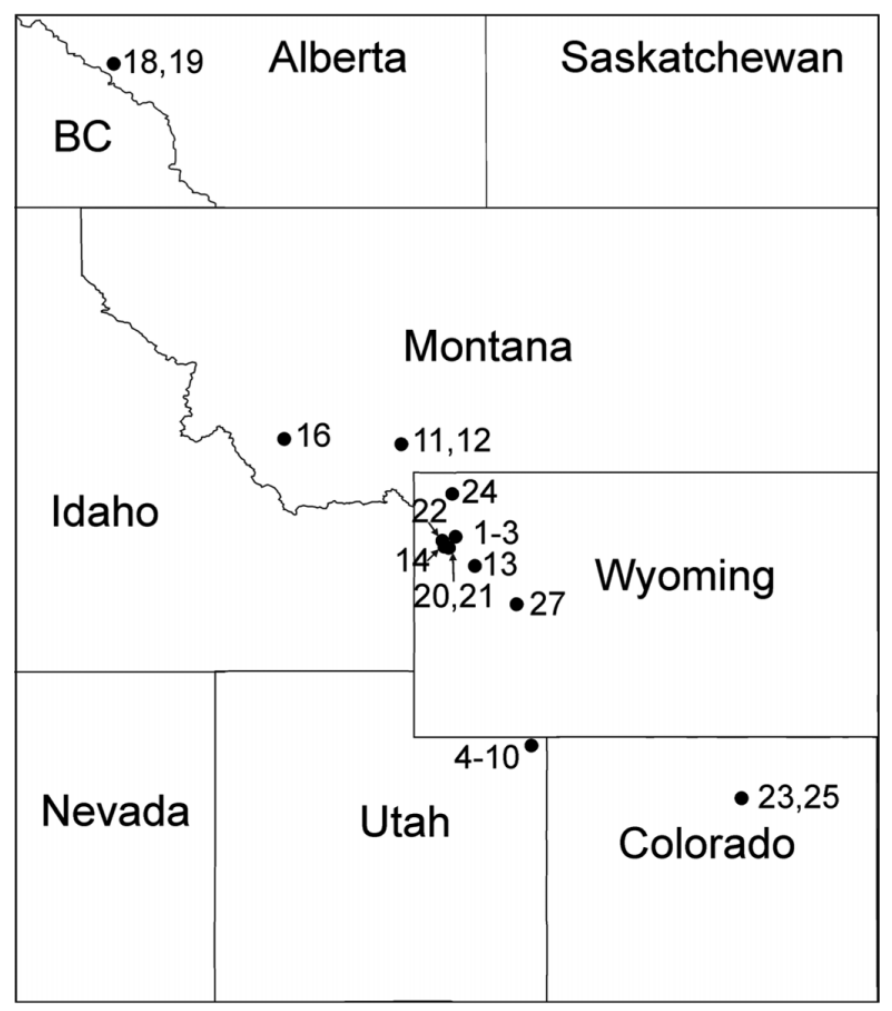

Fig. 2. Relationship between DBH and tree mortality based on data from 27 sites used in the meta-analyses. Sites were categorized based on their location (latitude, longitude, and elevation). Location factors are based on Shore and Safranyik (1992): 1.0, optimal conditions; 0.7 , suboptimal conditions; 0.3 , marginal conditions for the mountain pine beetle.

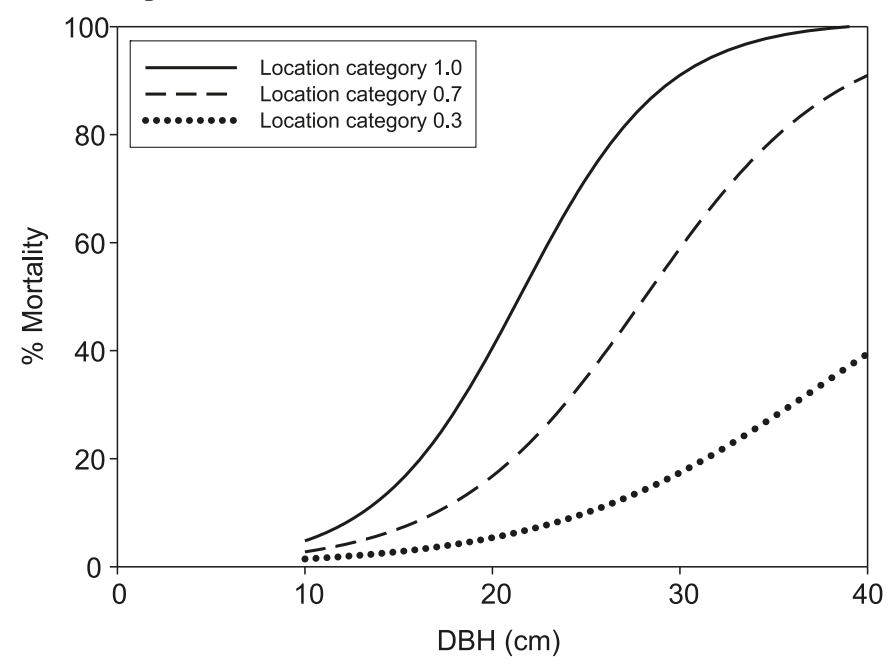

diameter a breast height (DBH) and attack frequency. There is, however, considerable variation in diameter-attack relationships obtained from different sites. We therefore sought to determine the magnitude and overall pattern of the relationship between tree diameter and mountain pine beetle caused mortality typically found in attacked lodgepole pine forests that shares certain characteristics.

We used meta-analysis in our review, since this technique provides a powerful quantitative tool for investigating general trends and patterns based on several studies (Arnqvist and Wooster 1995). While there are several potential disadvantages and limitations with meta-analysis, e.g., publication bias, there are procedures to deal with these problems (Wang and Bushman 1998; Gurevitch and Hedges 1999; Kotiaho and Tomkins 2002; Jennions et al. 2004).

Several factors influence mountain pine beetle caused tree mortality patterns. At higher elevations lodgepole pine trees suffer lower levels of mortality (measured as percentage of trees killed or basal area killed) (Amman 1972; Amman et al. 1973), presumably because the cooler climate causes a higher proportion of the beetle population to overwinter in more vulnerable stages, i.e., as eggs, or first or second instars (Amman et al. 1973). The latitude and longitude of a site may also influence mortality patterns, since temperatures are lower further to the north and east on the North American continent. According to Hopkins' bioclimatic law, an increase in elevation of $122 \mathrm{~m}$ equals a $1^{\circ}$ shift northward or a $5^{\circ}$ shift eastward (Hopkins 1920).

Forest managers need reliable decision tools to assign stand-level treatment priority. The most widely used model in British Columbia (Shore and Safranyik 1992; validated by Shore et al. 2000) uses average tree, stand, and geographic factors to predict potential relative losses of pine basal area in the event of an outbreak of the mountain pine beetle. They developed a formula, based on beetle survival at different elevations and Hopkins' bioclimatic law, to predict the influence of a site's location on beetle-caused tree mortality. They also developed a "density factor" to predict the influence of a site's tree density on beetle-caused tree mortality. The highest mortality is usually observed at intermediate stand densities (Anhold and Jenkins 1987). In addition, Shore and Safranyik (1992) used stand age as a parameter in their susceptibility model. In the present review we used meta-analysis of published data to evaluate the influence of these parameters on beetle-caused tree mortality.

Percent basal area killed has been used extensively as a metric of mortality, because it is a measure meaningful to forest managers, and it has been argued that the basal area of a tree is proportional to the "barrier" it constitutes to flying beetles, which, in turn, is thought to be related to the probability that a tree is attacked by beetles (Safranyik et al. 1975). Other measures of mortality such as number of trees killed per unit area have also been used (Schenk et al. 1977). Susceptibility-risk rating models use expected mortality based on average stand conditions as a metric to compare stands. This metric provides a measure that is useful for prioritizing management of stands in advance of an infestation, although it has limited value for accurately predicting mortality at the individual-stand level (Shore et al. 2006). Nevertheless, end users often assess the precision of susceptibility-risk rating against actual mortality and conclude that the model does not work when stand-level mortality estimates deviate significantly from actual mortality. Thus, there is a demand for improved mortality predictions in decision-support models. This demand may be met by an improved and generalized mortality measure. 
Table 2. Weighted meta-analyses using probability of death index for individual stands, i.e., average percent mortality for the DBH classes above $23 \mathrm{~cm}$, as effect sizes.

\begin{tabular}{|c|c|c|c|c|c|}
\hline Variable & Model & $\mathrm{df}^{a}$ & $Q^{b}$ & $P$ & $P_{\mathrm{adj}}^{c}$ \\
\hline \multirow[t]{3}{*}{ Continuous location parameter $^{d}$} & Regression & 1 & 14.08 & 0.0002 & $<0.05$ \\
\hline & Residual & 22 & 17.50 & & \\
\hline & Total & 23 & & & \\
\hline \multirow[t]{3}{*}{ Categorical location factor ${ }^{d}$} & Regression & 1 & 17.10 & $<0.0001$ & $<0.05$ \\
\hline & Residual & 22 & 14.48 & & \\
\hline & Total & 23 & & & \\
\hline \multirow[t]{3}{*}{ Categorical location factor ${ }^{d}$ (subset) ${ }^{e} \times$ density factor } & Regression & 1 & 5.76 & 0.02 & $<0.05$ \\
\hline & Residual & 13 & 13.31 & & \\
\hline & Total & 14 & & & \\
\hline \multirow[t]{3}{*}{ Categorical location factor $^{d}$ (subset) $)^{e}$} & Regression & 1 & 18.27 & $<0.0001$ & $<0.05$ \\
\hline & Residual & 13 & 8.56 & & \\
\hline & Total & 14 & & & \\
\hline \multicolumn{6}{|l|}{${ }^{a}$ Degrees of freedom. } \\
\hline \multicolumn{6}{|l|}{${ }^{b}$ Heterogeneity. } \\
\hline \multicolumn{6}{|c|}{${ }^{c}$ Adjusted for several simultaneous tests with sequential Bonferroni corrections. } \\
\hline \multicolumn{6}{|c|}{${ }^{d}$ Determined based on elevation, latitude, and longitude (based on Shore and Safranyik (1992). } \\
\hline
\end{tabular}

In the following we propose and evaluate a new mortality measure, the probability of death index, where we exploit the relationship between tree diameter and beetle-caused tree mortality. The index reflects the probability that a tree with a diameter larger than $23 \mathrm{~cm}$ will die. Only trees larger than $23 \mathrm{~cm}$ were included, since it has been shown that smaller trees are rarely attacked, unless they are close to a larger tree (Mitchell and Preisler 1991). This attack pattern may be because, in most cases, such trees will not even yield replacement numbers of beetles (Brown 1956; Cole and Amman 1969; Safranyik et al. 1975). Optimal brood productivity also occurs in trees with a DBH of $23 \mathrm{~cm}$ or larger (N. Björklund and B.S. Lindgren, unpublished data).

Beetle population levels may affect the diameter distribution of mortality, but since no information about population levels was available from the studies included in the metaanalysis, we could not evaluate their potential influence. Western North America is currently experiencing the largest outbreak of the mountain pine beetle in recorded history (Westfall and Ebata 2008). During such extreme circumstances normal decision-support systems fail to predict mortality levels (Shore et al. 2006), and it is necessary to take largearea mountain pine beetle processes into account (Robertson et al. 2008). Predictive modeling, based on diameter-related mortality patterns, is unlikely to be useful during "hyperepidemic" conditions, so our meta-analysis does not include data from the current outbreak. In the following we refer to relationships that are relevant during normal outbreak conditions.

The objectives of our study were to determine $(i)$ whether there is a significant and predictable relationship between DBH and percent mortality, (ii) the general mortality patterns for sites within Shore and Safranyik's (1992) three categories based on the sites location (elevation, latitude, and longitude), and (iii) to what extent a site's location, tree density, and age can explain the observed mortality levels.

\section{Materials and methods}

To obtain data on the relationship between DBH and mountain pine beetle caused mortality levels, we searched ISI Web of Knowledge and JSTOR using the key words "mountain pine beetle" and "Dendroctonus ponderosae", along with "diameter", "DBH", and "D.B.H.". To find additional data, titles from the recovered articles were entered in the "Times Cited" function in ISI Web of Knowledge and the "Cited by..." function in Google ${ }^{\mathrm{TM}}$ Scholar beta, and reference lists were reviewed. We included all peer-reviewed and non-peer-reviewed published studies that reported mountain pine beetle caused mortality levels for individual diameter classes of lodgepole pine. Altogether, we located 15 studies that reported mortality levels from 27 sites (Table 1).

For every site we obtained (see below) the percent mortality for each DBH class. We assumed that mortality reported in these studies represented the maximum mortality at the end of the outbreak. In cases where the data had to be determined from graphs, digital photographs were taken using the macro lens setting on a Sony ${ }^{\circledR}$ Cyber-shot ${ }^{\circledR}$ DSC-T1 camera. The data were subsequently assessed visually on the screen from enlarged copies of the graphs using Microsoft ${ }^{\complement}$ PowerPoint ${ }^{\complement}$. In one study (Amman and Baker 1972), the mortality data were obtained from nonlinear "survival curves". In an attempt to avoid strong influence of random events, DBH classes with fewer than 25 trees/ha were excluded. The location parameters (Shore et al. 2006) were estimated using topographical maps from TopoZone.com ${ }^{\circ}$. Tree density was defined as the number of stems $\geq 7.5 \mathrm{~cm}$ DBH per hectare, and the density factor was calculated according to Shore et al. (2006).

Meta-analyses were performed using MetaWin, version 2 (Rosenberg et al. 2000). The percent mortality values were probit transformed to fulfill the requirement of linearity. When appropriate we used normal quantile plots to test 
Fig. 3. Probability of death index (average percent mortality for the DBH classes above $23 \mathrm{~cm}$ ) for lodgepole pine as a function of $(a)$ the categorical location factor, and $(b)$ the continuous location parameter (see Table 2 for test statistics).
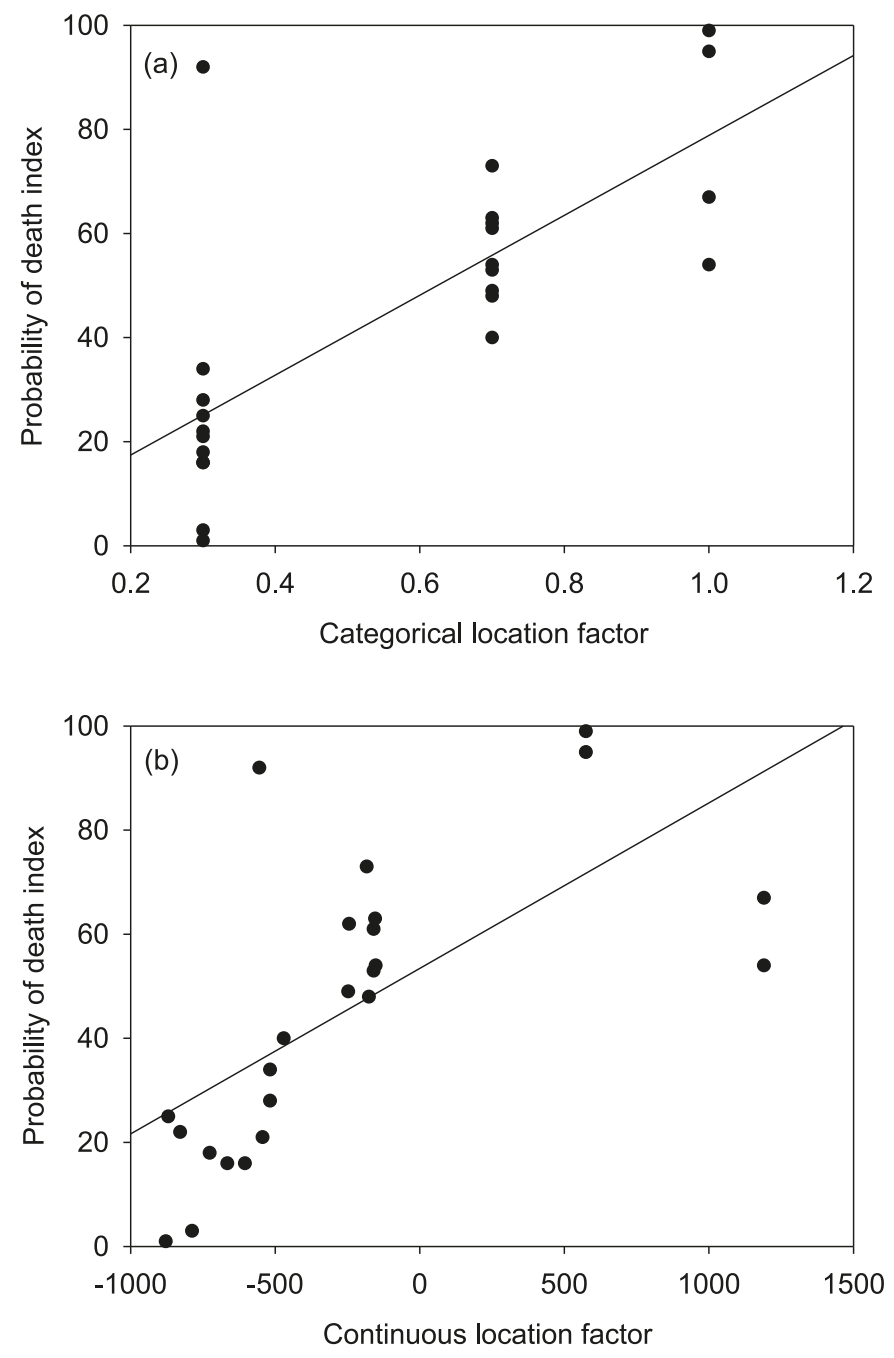

whether the normality assumptions were met, whether the studies came from a single population, and whether there was any publication bias (Wang and Bushman 1998). Failsafe numbers were calculated with Rosenthal's method (Rosenthal 1979) to estimate the magnitude of the filedrawer problem, e.g., publication of research results may depend on whether the direction of the results is consistent with earlier studies.

A meta-analysis was performed to determine whether there was a significant correlation between DBH and percent mortality. To standardize data to a common scale individual effect sizes were calculated for each site. An effect size is a statistical measure of the strength of the effect of the independent variable on the dependent variable. We used Fischer's Z-transformed correlation coefficients $(Z r)$ as effect sizes, and the variance was calculated based on the number of observations. A random-effects model was used to calculate the mean effect size, and significance levels were obtained from randomization procedures with 4999 iterations.
The overall relationships were considered significant if the 95\% confidence limit did not bracket zero.

To investigate the general DBH versus percent mortality pattern for the three location categories, the slopes and intercepts of the linear regressions were used as effect sizes (Hillebrand 2004). A random-effects model was used with the location category as a grouping variable. The weighted average mean slope and intercept values for each location category were then transformed from probit values to percentages.

A novel tree mortality measure, the probability of death index, was developed and evaluated. It was defined as the average proportion of trees killed for DBH classes above $23 \mathrm{~cm}$. Because of the variation among studies in how the data were divided into DBH classes, we used the average value of each DBH class for trees $>23 \mathrm{~cm}$ DBH. To be useful as a tool for forest managers, it must be possible to predict the probability of death index from stand parameters that are easy to measure. To this end we used the location (elevation, latitude, and longitude), density, and age factors developed by Shore and Safranyik (1992) as potential modifiers of the index. The impact of the potential modifiers was investigated using random-effects models with the probability of death index for individual stands as effect sizes, weighted by the number of trees that were surveyed (Côté et al. 2005). If the pooled variance estimate was less than or equal to zero, the random-effects model was not relevant, and a fixed-effects model was calculated in its place (Rosenberg et al. 2000).

Four separate analyses were performed with the following model variables: $(i)$ the continuous location parameter, (ii) the categorical location factor, (iii) the categorical location factor times the density factor, and (iv) the categorical location factors from the sites where the density factor also could be calculated (to investigate whether the density factor explained any additional part of the variance). Since several statistical tests were performed, we used sequential Bonferroni corrections (Holm's method) to calculate tablewide significance levels (Rice 1989).

\section{Results}

The normal quantile plots showed that all sites, except one, fell on a straight line within the $95 \%$ confidence interval bands, without "bumps" or gaps. This indicates that the normality assumption was met by the data we used, that the studies can be considered to come from a single population, and that there is no strong publication bias. This was the case when both the Fischer's Z-transformed correlation coefficients and the probability of death index for individual stands were used as effect sizes. The fail-safe number calculation, Rosenthal's method, for the analysis with correlation coefficients showed that 1656 studies with nonsignificant results need to be added to change the result to nonsignificance.

Overall, the mean correlation between $\mathrm{DBH}$ and percent mortality was significantly positive $\left(E^{++}\right.$(grand mean effect size $)=2.11, Q_{\text {tot }}($ total heterogeneity $)=28.61,95 \% \mathrm{CI}=$ 2.14-2.17). This was the case even when studies with several sites (see Table 1$)$ were excluded $\left(E^{++}=2.20, Q_{\text {tot }}=\right.$ $5.83,95 \% \mathrm{CI}=1.93-2.47)$. 
The analyses of the weighted average mortality patterns over DBH for the three location categories of Shore and Safranyik (1992) showed that the relationships could be described by the following sigmoid equations (Fig. 2).

Location category 1.0:

$$
\text { [1] } \quad y=101 /[1+\exp (-(x-21.5) / 3.84)]
$$

Location category 0.7 :

$$
\text { [2] } \quad y=100 /[1+\exp (-(x-28.1) / 5.09)]
$$

Location category 0.3 :

$$
\text { [3] } \quad y=68 /[1+\exp (-(x-37.6) / 7.19)]
$$

where $y$ is percent tree mortality, and $x$ is DBH.

The mortality levels were generally low $(<4 \%)$ for trees with $\mathrm{DBH}<10 \mathrm{~cm}$, regardless of the location category (Fig. 2). Mortality increased rapidly with increasing DBH for sites in the locations most favourable to beetle survival, and at a DBH of approximately $30 \mathrm{~cm}$, mortality level reached an upper asymptote that was close to $100 \%$. For sites in less favourable locations the increase in mortality was slower, and there was no distinct upper asymptote. The magnitude of the average difference in mortality among sites within the most and least favourable locations was huge for large trees, e.g., $91 \%$ of trees with a DBH of $30 \mathrm{~cm}$ died in the locations most favourable to the beetles, whereas the corresponding figure for the least favourable locations was only $18 \%$. The fastest published increase in tree mortality for a single site is a $7 \%$ increase in mortality per centimetre of $\mathrm{DBH}$ increase, and the slowest increase of mortality is less than $0.01 \%$ per centimetre (Table 1 ).

The results of the four meta-analyses, where the probability of death index for individual stands was used as effects sizes, are shown in Table 2. We also attempted to use stand age as a parameter, but age was only reported from four sites, which is not sufficient to permit an analysis. The continuous location parameter explained $45 \%$ of the variation in the probability of death index (Fig. $3 b$ ), and the categorical location factor explained slightly more, i.e., $53 \%$ (Fig. $3 a$ ). For the subset of sites where both the categorical location factor and the density factor could be determined, these two factors, when multiplied with each other, only explained $30 \%$ of the variation. By comparison, the categorical location factor by itself, for the same sites, explained $68 \%$ of the variation. All four tests were significant even after sequential Bonferroni corrections (Table 2).

\section{Discussion}

Our meta-analysis demonstrated a general and statistically significant relationship between the diameter of lodgepole pines and the percent mountain pine beetle caused tree mortality. This finding is extremely robust given the high failsafe number, i.e., more than 1600 nonsignificant studies need to be added to change the result. In accordance with this result, the correlations between diameter and percent beetle caused tree mortality were positive for all sites.

Mortality levels for trees smaller than $10 \mathrm{~cm} \mathrm{DBH}$ were below $4 \%$ for all location categories (Fig. 2). Small trees may be attacked because incoming beetles switch from at- tacking a large tree to attacking a small tree close by (Geiszler and Gara 1978; Mitchell and Preisler 1991). If there are high densities of small diameter trees, $4 \%$ can constitute a large number of trees, and in individual stands the mortality levels can be much higher (Cole and Cahill 1976). Nevertheless, our meta-analysis shows that only a minor proportion of the small-diameter trees will normally be attacked during an epidemic.

It has been suggested that epidemics do not end until "all" trees above $15.2 \mathrm{~cm}$ (Tunnock 1970) or above $23 \mathrm{~cm}$ (Preisler 1993) are killed. Based on our meta-analyses, as illustrated in Fig. 2, such high mortality rates are uncommon under normal epidemic conditions. For stands in the category with the highest mortalities, only trees above $30 \mathrm{~cm}$ DBH generally reached mortality levels close to $100 \%$. Stands in smaller DBH categories usually did not reach such high mortality levels. It is important to note that outbreaks may end as a result of factors other than host depletion. This was particularly true for stands in the location categories 0.3 and 0.7 . For example, unfavourable climatic conditions may lead to a loss of population synchrony (Logan and Powell 2004), which favours the host tree, i.e., the probability of beetles successfully overcoming host defences is reduced. In addition, some studies may not have followed the outbreak to its conclusion; in which case the mortality reported would be lower than it should have been.

Coulson (1979) suggested that "In stands with mixed diameter classes the percentage of trees killed during outbreaks is related to tree diameter, with the greatest number of trees being killed in the diameter class representing the highest basal area". This may not be a strictly causal relationship but rather a consequence of the typical diameter distribution of an attacked lodgepole pine stand. Consider, for example, a hypothetical stand that falls within location category 1.0 (Shore and Safranyik 1992) and has one hundred $20 \mathrm{~cm} \mathrm{DBH}$ trees per hectare and thirty $50 \mathrm{~cm} \mathrm{DBH}$ trees per hectare. The total basal area for the $20 \mathrm{~cm}$ trees is $3.14 \mathrm{~m}^{2}$, which is lower than the corresponding $5.89 \mathrm{~m}^{2}$ for the $50 \mathrm{~cm}$ trees. The expected mortality, according to Fig. 2, for the $20 \mathrm{~cm} \mathrm{DBH}$ trees is 40 trees/ha (40\%), which is greater than the corresponding 30 trees/ha $(100 \%)$ for the $50 \mathrm{~cm}$ trees. Thus, in this hypothetical stand we would not expect the greatest number of trees killed to occur in the diameter class with the highest basal area.

We contend that compared with other mortality measures there are two potential advantages with the new metric, the probability of death index, that we suggested and evaluated in this study. First, it is a sensitive measure, since it only includes trees that are important in maintaining or accelerating an outbreak, i.e., pines $\geq 23 \mathrm{~cm}$ DBH. Second, the probability of death index is the only measure, to our knowledge, that is independent of the absolute number of trees in any one DBH class, e.g., the same rating is obtained if, within a given diameter class, 10 of 20 trees/ha or 20 of 40 trees/ha die. By comparison, if the percentage of the basal area killed within a stand is used (Shore and Safranyik 1992), the effect on a mortality index of doubling the number of trees killed within a diameter class will depend on the diameter classes affected, since the relative effect of large trees is disproportionately large compared with the relative effect of smaller trees. 
The novel tree mortality measure, the probability of death index, could be predicted with a reasonable accuracy based solely on where the site is located, i.e., its location factor (Fig. $3 b$ ). The relatively high precision may be due to the index only including trees that are significant for sustaining an epidemic, i.e., $>23 \mathrm{~cm} \mathrm{DBH}$, and the fact that it is not dependent of the absolute number of trees in any one diameter class. From an applied point of view, such trees can now be identified based on remote sensing information that is already collected for other purposes, e.g., growth simulators (Packalén and Maltamo 2008). A potential disadvantage with the index is that the mortality for trees with a DBH below $23 \mathrm{~cm}$ has to be estimated in a second step. This can, however, easily be done based on the general mortality patterns shown in Fig. 2. For metrics based on basal area the relative influence of large trees is disproportionately large, which is appealing to forest managers, since large trees are relatively more important from both a timber management and a beetle productivity point of view. This issue can easily be compensated for if the probability of death index has an improved precision compared with basal area based mortality predictions. Unfortunately, we could not compare the performance of the new index with that of the mortality measure used by Shore and Safranyik (1992), since the data necessary to calculate their mortality measure was not available, e.g., stand age. Thus, future research is necessary to evaluate the performance of the probability of death index compared with that of other mortality measures.

Interestingly, the categorical location factor explained more of the variation in the probability of death index than the continuous equivalent. Examining Figs. $3 a$ and $3 b$ reveals that this result is, in part, due to a decline in the probability of death index for the highest location factor score. When categorizing this variable, the effect of these points is reduced, because it is offset by the high probability of death index scores for the other two stands in this category. The decline in the index may be real, however. Logan and Powell (2004) demonstrated through modeling that if temperatures are too high, mountain pine beetle population synchronization breaks down in a fashion similar to when temperatures are too low. Carroll et al. (2004) showed that a shift in the occurrence of mountain pine beetle outbreaks occurred with warming climate, leading to increasing outbreak frequency in areas with previously unsuitable climatic conditions, and a decline has been observed in previously suitable areas. Thus, the relationship shown in Fig. $3 b$ could possibly be curvilinear, in which case a continuous location variable would provide a better explanation. However, because few data points had high location scores, we are unable to determine whether this was the case with any level of confidence.

The location factor as developed by Shore and Safranyik (1992) and used here is based on data largely collected before the current warming trend. Carroll et al. (2004) developed a climatic suitability index, which has a higher resolution than the location factor and is based on 30 year climate normals. These data change with changing conditions, whereas the location factor of Shore and Safranyik (1992) does not. Thus, mortality levels currently occurring in areas with low location factors may be underestimated and Carroll et al.'s (2004) climatic suitability classes may be a better modifier for susceptibility-risk rating models. In fact, climatic suitability class will be used in future models (T.L. Shore, personal communication, $2008^{3}$ ). We could not use this classification in our study, since we could not obtain the appropriate data for the studies we used.

The density factor (Shore and Safranyik 1992) did not explain any additional part of the variation in the probability of death index. This result is especially interesting, since the index is independent of the absolute number of trees affected in any one DBH class. However, the impact of the density factor is complicated by the fact that it is related to the tree diameter distribution, and the sample size for this test was rather limited; thus, further data and analysis are needed before any definitive conclusions can be drawn.

Tree density may be relatively more important at a local scale where the influence of the location factor is lower. In support of this hypothesis Negrón et al. (2008), in a study where the sampling sites were relatively close to each other, showed that ponderosa pine trees (Pinus ponderosa) experience higher probability of being attacked by mountain pine beetles in areas with high stand densities. They also used logistic regression to evaluate the influence of site characteristics on bark beetle caused tree mortality by modeling the relationship between $\mathrm{DBH}$ and percent tree mortality (this approach was first described in a report preceding the current article (Björklund and Lindgren 2007)).

We could not evaluate the influence of stand age, since that information was only provided in 4 of the 27 sites we examined. However, since age is correlated with $\mathrm{DBH}$, which is already incorporated in the probability of death index, we would not expect a strong influence of age. The data we used for this meta-analysis came from unmanaged stands, and we would therefore anticipate a relatively good correlation between age and DBH (T. Cudmore, unpublished).

The relationships between $\mathrm{DBH}$ and percent mortality may be useful for estimating potential threats to stands and for predicting stand depletion. The approach used in this study to measure the stand-level impact of an outbreak may also prove to be useful for other bark beetle - tree species ecosystems.

\section{Acknowledgments}

This project was funded by the Government of Canada through the Mountain Pine Beetle Initiative, a six year, \$40 million program administered by Natural Resources Canada, Canadian Forest Service, and an Natural Science and Engineering Research Council Discovery Grant to B.S.L. We thank Barbara J. Bentz, Tim Cudmore, Ken Gibson, Simon Goring, Sandra Kegley, Les Safranyik, and Greg Smith for help with locating copies of hard-to-get relevant papers. Julia Koricheva is acknowledged for valuable advice regarding the meta-analysis and a helpful review of the draft manuscript. We are also grateful to two anonymous referees for their comments, which were helpful in improving the paper.

\footnotetext{
${ }^{3}$ Research Scientist, Canadian Forest Service, Pacific Forestry Centre, Victoria, British Columbia, Canada.
} 


\section{References}

Amman, G.D. 1969. Mountain pine beetle emergence in relation to depth of lodgepole pine bark. USDA For. Serv. Res. Note INT96.

Amman, G.D. 1972. Mountain pine beetle brood production in relation to thickness of lodgepole pine phloem. J. Econ. Entomol. 65: $138-140$.

Amman, G.D., and Baker, B.H . 1972. Mountain pine beetle influence on lodgepole pine stand structure. J. For. 70: 204-209.

Amman, G.D., Baker, B.H., and Stipe, L.E. 1973. Lodgepole pine losses to mountain pine beetle related to elevation. USDA For. Serv. Res. Note INT-171.

Anhold, J.A., and Jenkins, M.J. 1987. Potential mountain pine beetle (Coleoptera: Scolytidae) attack of lodgepole pine as described by stand density index. Environ. Entomol. 16: 738-742.

Arnqvist, G., and Wooster, D. 1995. Meta-analysis: synthesizing research findings in ecology and evolution. Trends Ecol. Evol. 10: 236-240. doi:10.1016/S0169-5347(00)89073-4.

Björklund, N., and Lindgren, B.S. 2007. Diameter of lodgepole pine and mortality caused by the mountain pine beetle: factors that influence the relationship and their applicability for susceptibility rating. Mountain Pine Beetle Initiative Project No. 3.20, 3 April 2007, Final report.

Brown, G.S. 1956. Population trends in the mountain pine beetle at Windermere Creek, British Columbia. Interim Report 1954-6. Forest Biology Laboratory, Victoria, B.C.

Burnell, D.G. 1977. A dispersal-aggregation model for mountain pine beetle in lodgepole pine stands. Res. Popul. Ecol. (Kyoto), 19: 99-106. doi:10.1007/BF02510942.

Carroll, A.L., Taylor, S.W., Régnière, J., and Safranyik, L. 2004. Effects of climate change on range expansion by the mountain pine beetle in British Columbia. In Mountain Pine Beetle Symposium: Challenges and Solutions. Edited by T.L. Shore, J.E. Brooks, and J.E. Stone. Can. for. Serv. Info. Rep. BC-X-399. pp. 223-232.

Cole, W.E. 1975. Interpreting some mortality factor interactions within mountain pine beetle broods. Environ. Entomol. 4: 97102.

Cole, W.E. 1981. Some risks and causes of mortality in mountain pine-beetle populations - a long-term analysis. Res. Popul. Ecol. (Kyoto), 23: 116-144. doi:10.1007/BF02514096.

Cole, W.E., and Amman, G.D. 1969. Mountain pine beetle infestations in relation to lodgepole pine diameters. USDA For. Serv. Res. Note INT-95.

Cole, W.E., and Cahill, D.B. 1976. Cutting strategies can reduce probabilities of mountain pine beetle epidemics in lodgepole pine. J. For. 74: 294-297.

Côté, I.M., Gill, J.A., Gardner, T.A., and Watkinson, A.R. 2005. Measuring coral reef decline through meta-analyses. Philos. Trans. R. Soc. Lond. B Biol. Sci. 360: 385-395. doi:10.1098/ rstb.2004.1591. PMID:15814352.

Coulson, R.N. 1979. Population-dynamics of bark beetles. Annu. Rev. Entomol. 24: 417-447. doi:10.1146/annurev.en.24.010179. 002221.

Evenden, J.C., and Gibson, A.L. 1940. A destructive infestation in lodgepole pine stands by the mountain pine beetle. J. For. 38: 271-275.

Geiszler, D.R., and Gara, R.I. 1978. Mountain pine beetle attack dynamics in lodgepole pine. In Theory and practice of mountain pine beetle management in lodgepole pine forests. Edited by A.A. Berryman, G.D. Amman, and R.W. Stark. University of Idaho, Moscow, Idaho. pp. 182-187.

Geiszler, D.R., Gara, R.I., Driver, C.H., Gallucci, V.F., and Martin, R.E. 1980. Fire, fungi and beetle influence on a lodgepole pine ecosystem of south-central Oregon. Oecologia (Berl.), 46: 239243. doi:10.1007/BF00540132.

Gibson, A.L. 1936. Report of the surveys of the mountain pine beetle infestation on the Beaverhead National Forest 1935. Forest Insect Laboratory, Coeur d'Alene, Idaho.

Gurevitch, J., and Hedges, L.V. 1999. Statistical issues in ecological meta-analyses. Ecology, 80: 1142-1149.

Hillebrand, H. 2004. Strength, slope and variability of marine latitudinal gradients. Mar. Ecol. Prog. Ser. 273: 251-267. doi:10. 3354/meps273251.

Hopkins, A.D. 1920. The bioclimatic law. Mon. Weather Rev. 48: 355-355. doi:10.1175/1520-0493(1920)48<355a:TBL >2.0.CO;2.

Hopping, G.R., and Beall, G. 1948. The relation of diameter of lodgepole pine to incidence of attack by the bark beetle Dendroctonus monticolae Hopkins. For. Chron. 24: 141-145.

Hynum, B.G., and Berryman, A.A. 1980. Dendroctonus ponderosae (Coleoptera: Scolytidae): pre-aggregation landing and gallery initiation on lodgepole pine. Can. Entomol. 112: 185-191.

Jennions, M.D., Moller, A.P., and Hunt, J. 2004. Meta-analysis can "fail": reply to Kotiaho and Tomkins. Oikos, 104: 191-193. doi:10.1111/j.0030-1299.2004.12265.x.

Katovich, S.A., and Lavigne, R.J. 1986. The applicability of available hazard rating systems for mountain pine beetle in lodgepole pine stands of southeastern Wyoming. Can. J. For. Res. 16: 222 225. doi:10.1139/x86-039.

Klein, W.H. 1967. Forest insect conditions on the Teton National Forest and in Grand Teton National Park. USDA Forest Service Region 4. Division of Timber Management, Ogden, Utah.

Klein, W.H., Stipe, L.E., and Frandsen, L.V. 1972. How damaging is a mountain pine beetle infestation? A case study. USDA Forest Service Region 4, Division of Timber Management, Ogden, Utah.

Kotiaho, J.S., and Tomkins, J.L. 2002. Meta-analysis, can it ever fail? Oikos, 96: 551-553. doi:10.1034/j.1600-0706.2002.960316.x.

Logan, J.A., and Powell, J.A. 2004. Modelling mountain pine beetle phenological response to temperature. In Mountain Pine Beetle Symposium: Challenges and Solutions. Edited by T.L. Shore, J.E. Brooks, and J.E. Stone. Can. For. Serv. Info. Rep. BC-X399. pp. 210-222.

Mitchell, R.G., and Preisler, H.K. 1991. Analysis of spatial patterns of lodgepole pine attacked by outbreak populations of the mountain pine beetle. For. Sci. 37: 1390-1408.

Negrón, J.F., Allen, K., Cook, B., and Withrow, J.R. 2008. Susceptibility of ponderosa pine, Pinus ponderosa (Dougl. ex Laws.), to mountain pine beetle, Dendroctonus ponderosae Hopkins, attack in uneven-aged stands in the Black Hills of South Dakota and Wyoming USA. For. Ecol. Manage. 254: 327-334. doi:10.1016/j.foreco.2007.08.018.

Packalén, P., and Maltamo, M. 2008. Estimation of species-specific diameter distributions using airborne laser scanning and aerial photographs. Can. J. For. Res. 38: 1750-1760. doi:10.1139/ X08-037.

Parker, D.L. 1973. Trend of a mountain pine beetle outbreak. J. For. 71: 698-700.

Preisler, H.K. 1993. Modeling spatial patterns of trees attacked by bark-beetles. Appl. Stat. J. Royal Stat. Soc. Series C, 42: 501514.

Preisler, H.K., and Mitchell, R.G. 1993. Colonization patterns of the mountain pine beetle in thinned and unthinned lodgepole pine stands. For. Sci. 39: 528-545.

Reid, R.W. 1963. Biology of the mountain pine beetle, Dendroctonus monticolae Hopkins, in the east Kootenay region of British Columbia. III. Interactions between the beetle and its host, with 
emphasis on brood mortality and survival. Can. Entomol. 95: 225-238.

Rice, W.R. 1989. Analyzing tables of statistical tests. Evolution, 43: 223-225. doi:10.2307/2409177.

Robertson, C., Wulder, M.A., Nelson, T.A., and White, J.C. 2008. Risk rating for mountain pine beetle infestation of lodgepole pine forests over large areas with ordinal regression modelling. For. Ecol. Manage. 256: 900-912. doi:10.1016/j.foreco.2008.05. 054.

Roe, A.L., and Amman, G.D. 1970. The mountain pine beetle in lodgepole pine forests. USDA For. Serv. Res. Note INT-71.

Rosenberg, M.S., Adams, D.C., and Gurevitch, J. 2000. MetaWin: statistical software for meta-analysis. Version 2. Sinauer Associates, Sunderland, Mass.

Rosenthal, R. 1979. The "file drawer problem" and tolerance for null results. Psychol. Bull. 86: 638-641. doi:10.1037/00332909.86.3.638.

Rudinsky, J.A. 1962. Ecology of Scolytidae. Annu. Rev. Entomol. 7: 327-348. doi:10.1146/annurev.en.07.010162.001551.

Safranyik, L., Shrimpton, D.M., and Whitney, H.S. 1975. An interpretation of the interaction between lodgepole pine, the mountain pine beetle and its associated blue stain fungi in western Canada. In Management of lodgepole pine ecosystems. Vol. 1. Edited by D.M. Baumgartner. Symposium Proceedings, Washington State University, Pullman, Wash. pp. 406-428.

Schenk, J.A., Moore, J.A., Adams, D.L., and Mahoney, R.L. 1977. A preliminary hazard rating of grand fir stands for mortality by the fir engraver. For. Sci. 23: 103-110.

Shepherd, R.F. 1966. Factors influencing the orientation and rates of activity of Dendroctonus ponderosae Hopkins (Coleoptera: Scolytidae). Can. Entomol. 98: 507-518.

Shore, T.L., and Safranyik, L. 1992. Susceptibility and risk rating systems for the mountain pine beetle in lodgepole pine stands. For. Can. Info. Rep. BC-X-336.

Shore, T.L., Safranyik, L., and Lemieux, J.P. 2000. Susceptibility of lodgepole pine stands to the mountain pine beetle: testing of a rating system. Can. J. For. Res. 30: 44-49. doi:10.1139/cjfr30-1-44.

Shore, T.L., Riel, B.G., Safranyik, L., and Fall, A. 2006. Decision support systems. In The mountain pine beetle: a synthesis of biology, management, and impacts in lodgepole pine. Edited by L. Safranyik and B. Wilson. Natural Resources Canada, Canadian Forest Service, Pacific Forestry Center, Victoria, B.C. pp. 193-229.

Shrimpton, D.M., and Thomson, A.J. 1985. Relationship between phloem thickness and lodgepole pine growth characteristics. Can. J. For. Res. 15: 1004-1008. doi:10.1139/x85-161.

Stipe, L.E. 1973. Mountain pine beetle trend and impact study near Spring Creek Park, Bridger National Forest. USDA Forest Service Region 4. Division of Timber Management, Ogden, Utah.

Tunnock, S. 1970. A chronic infestation of mountain pine beetles in lodgepole pine in Glacier National Park, Montana. J. Entomol. Soc. B.C. 67: 23.

van Hees, W.W.S., and Holsten, E.H. 1994. An evaluation of selected spruce bark beetle infestation dynamics using point in time extensive forest inventory data, Kenai Peninsula, Alaska. Can. J. For. Res. 24: 246-251. doi:10.1139/x94-036.

Wang, M.C., and Bushman, B.J. 1998. Using the normal quantile plot to explore meta-analytical data sets. Psychol. Methods, 3: 46-54. doi:10.1037/1082-989X.3.1.46.

Westfall, J., and Ebata, T. 2008. 2007 summary of forest health conditions in British Columbia. Forest Practices Branch, British Columbia Ministry of Forests and Range, Victoria, B.C. pp. 172. 